
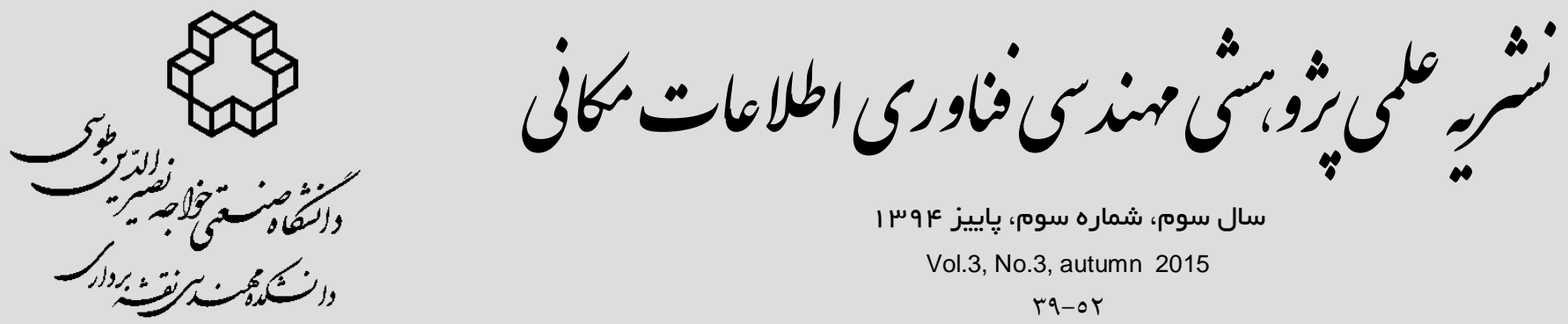

سال سوم، شماره سوم، ياييز ع سرן

Vol.3, No.3, autumn 2015

rq-or

آناليز سه بعدى استرين به روش لآحرانزى با سرىهاى زمانى ايستخاههاى دائمى

بدون پايدارسازى (منطقه مورد مطالعه : واشينكَتن)

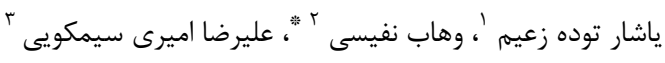

ا - دانشجوى كارشناسى ارشد زئودزى، كروه مهيندسى نقشهبردارى، دانشكده فنى و مهيندسى، دانشعاه اصفهان

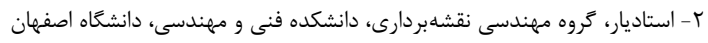

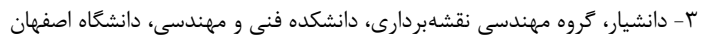

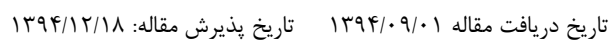

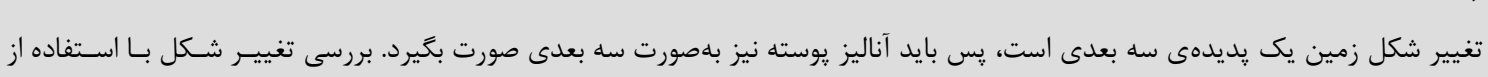

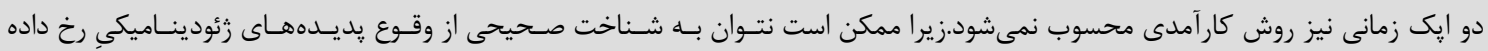

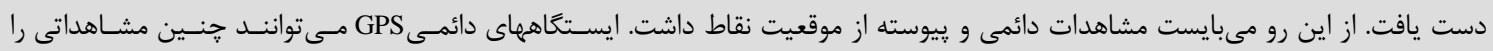

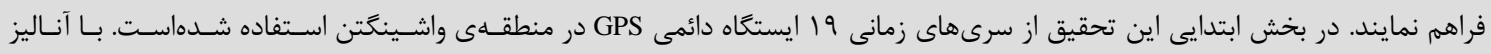

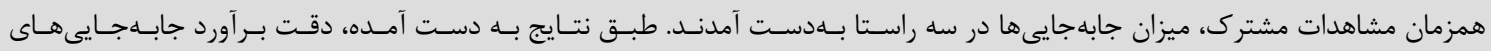

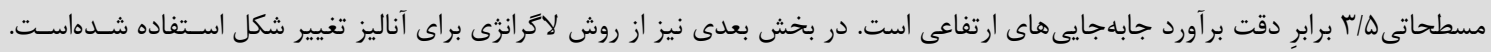

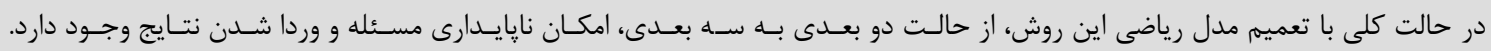

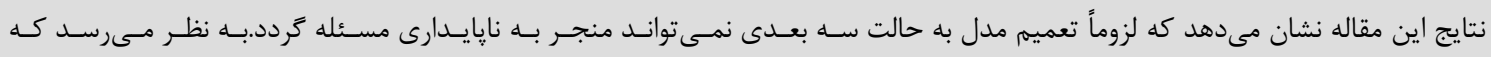

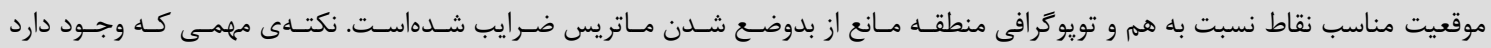

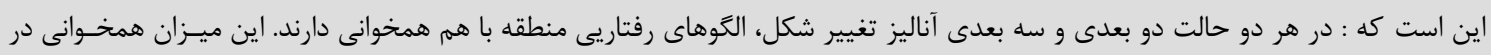

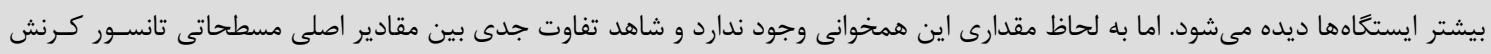

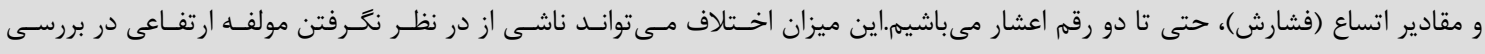
تغيير شكل به صورت دو بعدى باشد. 
اخير از جمله اميرى سيمكوئى و رى و همكاران روى

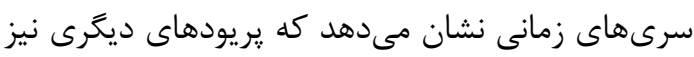

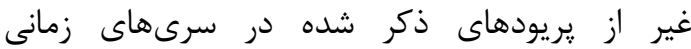
قابل مشاهده است، از جمله تغييرات با دوره تناوب

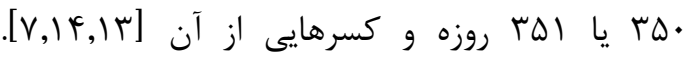

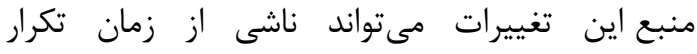

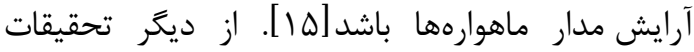
صورت گرفته در حوزهى تغيير شكل يوستهى زمين مى توان به مطالعات انجام شده توسط ترافارند، برونر،

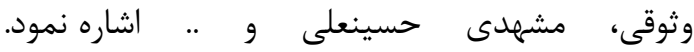

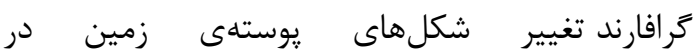

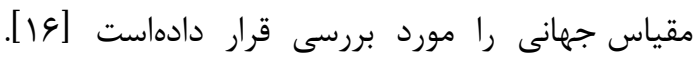
برونر ،روشى براى بررسى تغيير شكل كلى : يوستهى

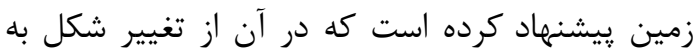

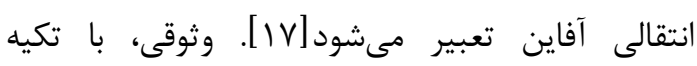
برمفاهيم نظريه يوسته در مكانيك محيطهاى ييوسته، روابط هندسه ذاتى و غيرذاتى تغيير شكل سطح زمين

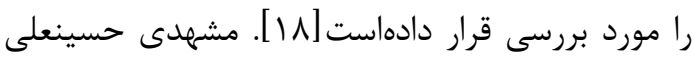
نيز با استفاده از روشهاى آيزويارامتريك و لآحرانزى و دراسي

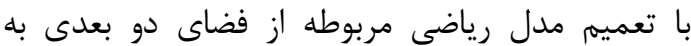
فضاى سه بعدى نشان مىدهد كه مسئله مورد نظر در

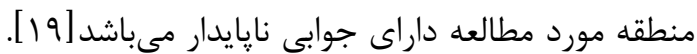
در اين مقاله ابتدا بهطور مختصر روابط مربوط به برآورد

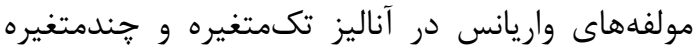

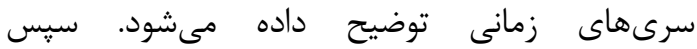
روابط مربوط به نكرش تغيير شكل لاكرانزى بلهصورت سه بعدى مورد بررسى قرار مى گيرد. در قسمت نتايج عددى نيز ميزان جابهجايىها در سه راستا برآورد

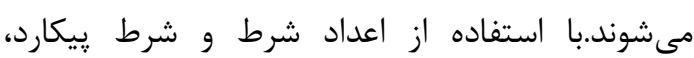
يايدارى مسئله مورد بررسى قرار مى ميرد. تانسور

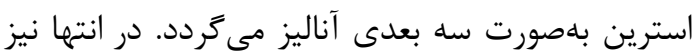
بلمنظور مقايسه، نتايج حالت سه بعدى و و حالت دو بعدى بررسى مىشود.

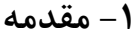

از اوايل قرن كذشته استفاده از اندازهيرىهاى زئودتيكى جهت رفتارسنجى يديدههاى زئوديناميكى از جمله تغيير شكل يوستهى زمين كاربرد وسيعى زئى

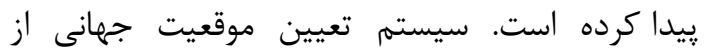
اواسط دهلى . 19V ميلادى بلهصورت كاربردى

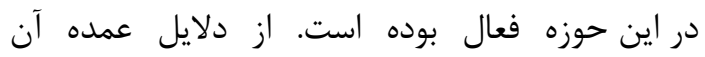
مى توان به عدم نياز به ديد مستقيم بين نقاط شبكه و تعيين موقعيت همزمان سهبعدى در هر شرايط آب و هوايى اشاره كرد ييوستكى سرىهاى زمانى (مشاهدات)

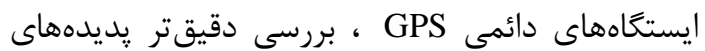

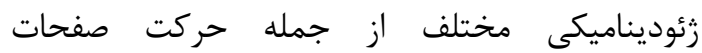

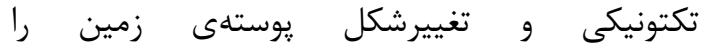

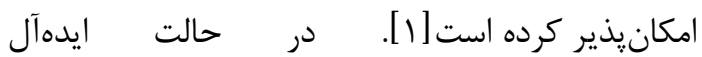
فرض مىشود سرىهاى زمانى فقط شامل نويز سفيد باشند ولى بررسى سرىهاى زمانى مختصاتى فئى نشان دادهاست كه نويز تنها از نوع سفيد نيست و

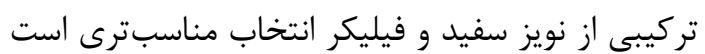

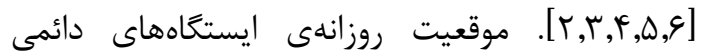
GPS علاوه بر تغييرات ثابت، تغييرات متناوبى از جمله

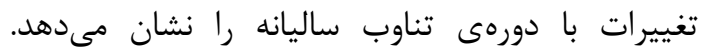

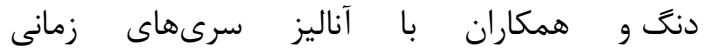
موقعيت روزانهى بيش از • TI ايستكاه دائمى GPS،

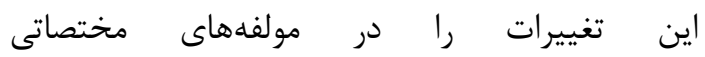

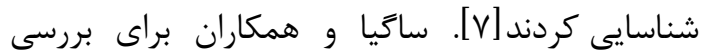
تغيير شكل يوستهى زمين سيخنالهاى سالانه و ترند خطى مربوط به سرىهاى زمانى را در نظر كرفتند. مشخص شد كه منبع سيخنالهاى غيرخطى در حركت واقعى زمين نيست و مربوط به آناليزها و اندازهكيرىهاي

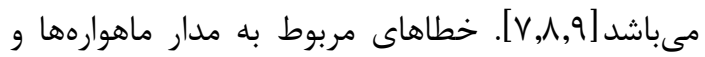

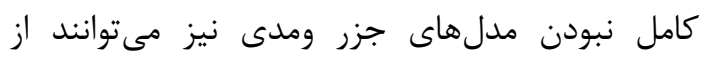
جملهى عوامل ديخر باشند. الكوهاى يريوديك سالانه،

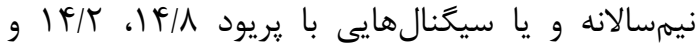

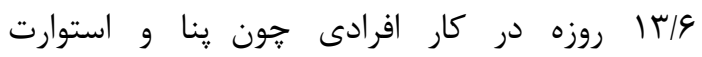

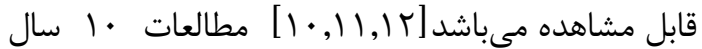


r- آناليز سرىهاى زمانى

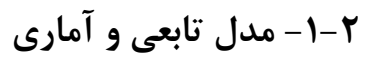

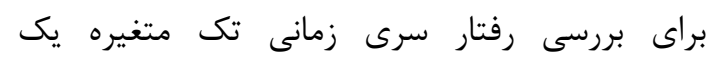

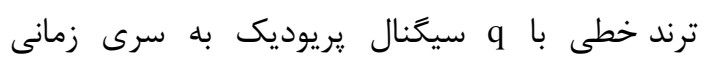

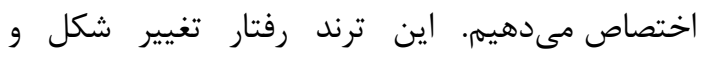

رابطه (1) $E\left(y_{i}(t)\right)=x_{i}^{(1)}+x_{i}^{(2)}(t)+\sum_{k=1}^{q}\left(x_{i}{ }^{(2 k-1)} \cos \omega_{k} t+x_{i}{ }^{(2 k)} \sin \omega_{k} t\right)$

(F) رابطه

$Q_{r w}=f_{s}^{-1}=\left[\begin{array}{cccc}1 & 1 & & 1 \\ 1 & 2 & \cdots & 2 \\ \vdots & & \ddots & \vdots \\ 1 & 2 & \cdots & m\end{array}\right]$

$f_{S}^{-1}=\frac{m-1}{T}$

كه در اين رابطه

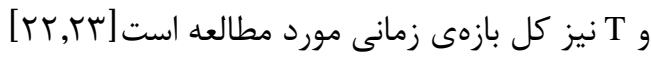

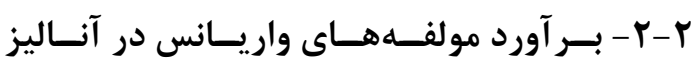

\section{تكمتغيره سرىهاى زمانى}

فرض كنيد مشاهدات تابعى از مدل خطى زمائ زماير باشد

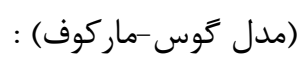

رابطه (م) (a)

$\mathrm{E}\{\underline{\mathrm{y}}\}=\mathrm{Ax} ; \mathrm{D}\{\underline{\mathrm{y}}\}=\mathrm{Q}_{\mathrm{y}}=\mathrm{Q}_{0}+\sum_{\mathrm{k}=1}^{\mathrm{p}} \sigma_{\mathrm{k}} \mathrm{Q}_{\mathrm{k}}$

كه در آن ماتريس A مرتبه كامل ستونى فرض شده، جزء معلوم ماتريس كوراريانس و

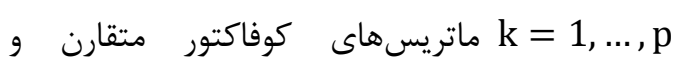

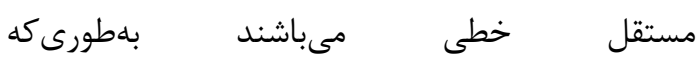

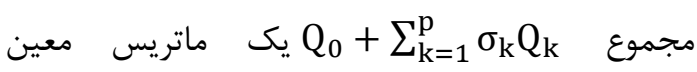
نامنفى باشد. در ابتدا برآورد مولفههاى واريانس براى براى

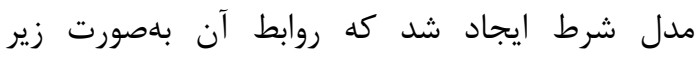
$\widehat{\widehat{\sigma}}=\mathrm{N}^{-1} l$ مىباشد [أ 14$]$ $\mathrm{n}_{\mathrm{kl}}=\operatorname{trace}\left(\mathrm{B}^{\mathrm{T}} \mathrm{Q}_{\mathrm{k}} \mathrm{BW}_{\mathrm{t}} \mathrm{B}^{\mathrm{T}} \mathrm{Q}_{1} \mathrm{BW}_{\mathrm{t}} \quad(\mathrm{V})\right.$
بردار مجهولات ضرايب توابع هارمونيك مىباشند.اكر سرى زمانى GPS در حالت كلى فلى شامل فيك

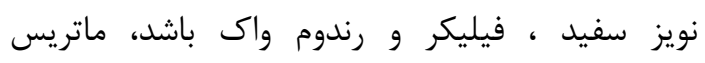

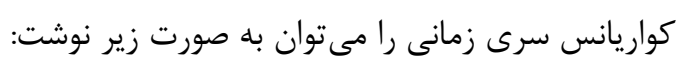

رابطه (T)

$Q_{y}=\sigma_{w}{ }^{2} \mathrm{I}+\sigma_{f}{ }^{2} Q_{f}+\sigma_{r w}{ }^{2} Q_{r w}$

در اين رابطه مولفههاى واريانسهاى مجهول نويز رندوم واك ، وايت وائ و فيليكر

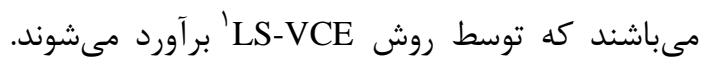

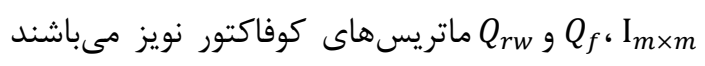
كه معلوم هستند. المانهاى ماتريس ييشنهاد زانخ و همكاران بهصورت زير بدست مئن آيند

رابطه (Г)

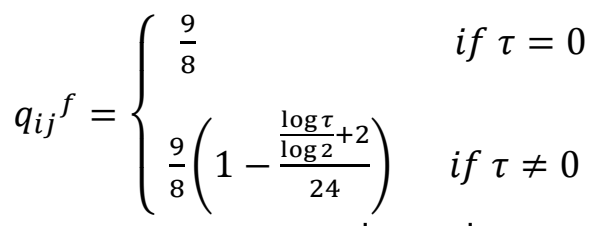

$$
\begin{aligned}
& \text { كه در اين رابطه }
\end{aligned}
$$

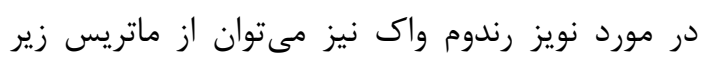

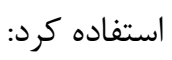

\footnotetext{
${ }^{1}$ Least Square Variance Component Estimation
} 
سرىهاى زمانى مختلف مى توانند بههم وابسته باشند،

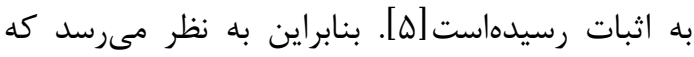
آناليز سرىهاى زمانى بلصورت مستقل و جداثانه جندان واقع بينانه نباشد. عمدتا در آناليزها يارامترهاى

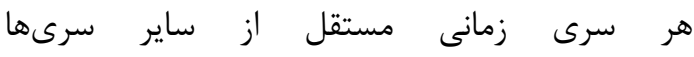
تخمين زده مىشود. با استفاده از مدل تكمتتغيره نمىتوان از همدى مشاهدات همزمان بهصورت بهينان

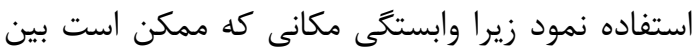
سرىهاى زمانى مختلف وجود داشته باشند

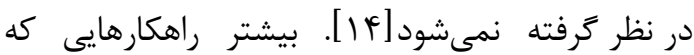
نتايج واقع بينانهاى به دنبال دارند، وابستگى هاى مكانى

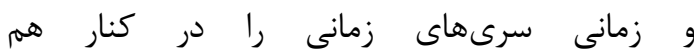
در نظر مى گيرند. اكر به جاى يك سرى زمانى همزمان سرى زمانى مورد بررسى قرار كيرد و مولفههاى

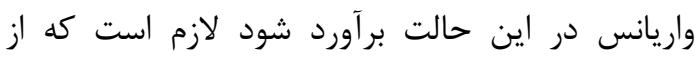
برآورد نويز كمترين مربعات در حالت جات جندمتغيره

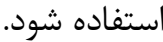
در اين حالت بردارهاى مشاهدات و مجهولات باصورت

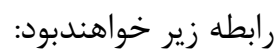

رابطه (ه) (1)

$\mathrm{Y}=\left[\mathrm{y}_{1}, \mathrm{y}_{2}, \ldots, \mathrm{y}_{\mathrm{r}}\right]$

$\mathrm{X}=\left[\mathrm{x}_{1}, \mathrm{x}_{2}, \ldots, \mathrm{x}_{\mathrm{r}}\right]$

مدل تصادفى در حالت جندمتغيره به صورت زير

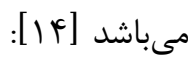

رابطه (19)

$Q_{v e c(\mathrm{Y})}=\Sigma \otimes \mathrm{Q}=\Sigma \otimes\left(\sum_{\mathrm{k}=1}^{\mathrm{P}} \sigma_{\mathrm{k}} \mathrm{Q}_{\mathrm{K}}\right)$

براى برآورد ماتريس كواريانس برآوردكرها (مجهول

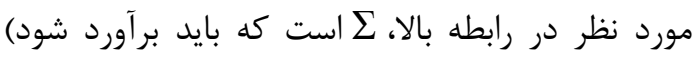

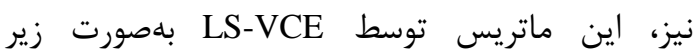

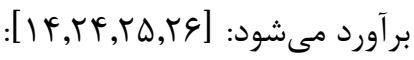

رابطه (ᄉ) (1) ()

( l)_k $=\llbracket$ t $^{\wedge} \mathrm{T}$ W_t B $\rrbracket^{\wedge} \mathrm{T}$ Q_k BW_t $-\mathrm{t}-$ $\operatorname{trace}\left(\mathrm{B}^{\wedge} \mathrm{T}\right.$ Q_k BW_t $\mathrm{B}^{\wedge} \mathrm{T}$ Q_0 BW_t) درصورتى كه ماتريس B (مدل معادلات شرط) معلوم باشد روش كمترين مربعات و رابطهى فوق براى

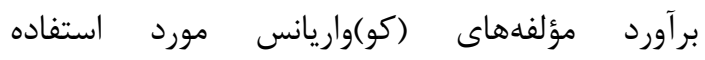
قرار مى گيرد. در بيشتر كاربردهاى زئودتيكى ماتريس طرح A موجود است. اتحاد زير بين مدل شرط و وردي

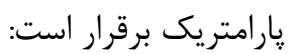
رابطه (9) برار (9) $A\left(A^{T} W A\right)^{-1} A^{T} W+W^{-1} B\left(B^{T} W^{-1} B\right)^{-1} B^{T}=I_{m}$ تعداد مشاهدات مىباشد.با استفاده از اتحاد فوق و m

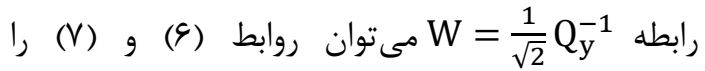

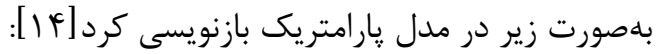
رابطه (•)

$\mathrm{n}_{\mathrm{kl}}=\frac{1}{2} \operatorname{tr}\left(\mathrm{Q}_{\mathrm{k}} \mathrm{Q}_{\mathrm{y}}^{-1} \mathrm{P}_{\mathrm{A}}^{\perp} \mathrm{Q}_{\mathrm{l}} \mathrm{Q}_{\mathrm{y}}^{-1} \mathrm{P}_{\mathrm{A}}^{\perp}\right.$ رابطه (1)

$\underline{\mathrm{L}}_{\mathrm{k}}=$

$\frac{1}{2} \hat{\mathrm{e}}^{\mathrm{T}} \mathrm{Q}_{\mathrm{y}}^{-1} \mathrm{Q}_{\mathrm{k}} \mathrm{Q}_{\mathrm{y}}^{-1} \underline{\mathrm{e}}-$ $\frac{1}{2} \operatorname{tr}\left(\mathrm{Q}_{\mathrm{k}} \mathrm{Q}_{\mathrm{y}}^{-1} \mathrm{P}_{\mathrm{A}}^{\perp} \mathrm{Q}_{0} \mathrm{Q}_{\mathrm{y}}^{-1} \mathrm{P}_{\mathrm{A}}^{\perp}\right)$

كه در اين روابط - - مابط

رابطه (r)

$\mathrm{P}_{\mathrm{A}}^{\perp}=\mathrm{I}-\mathrm{A}\left(\mathrm{A}^{\mathrm{T}} \mathrm{Q}_{\mathrm{y}}^{-1} A\right)^{-1} \mathrm{~A}^{\mathrm{T}} \mathrm{Q}_{\mathrm{y}}^{-1}$

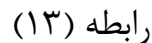

$\underline{\hat{\mathrm{e}}}=\mathrm{P}_{\mathrm{A}}^{\perp} \underline{\mathrm{y}}$

برآورد كمترين مؤلفههاى (كو)واريانس برحسب

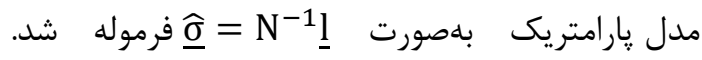
معكوس ماتريس نرمال (N) نيز ماتريس(كو)واريانس برآوردگرها را نتيجه مى دهد.

$\mathrm{Q}_{\widehat{\sigma}}=\mathrm{N}^{-1}$

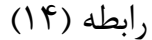

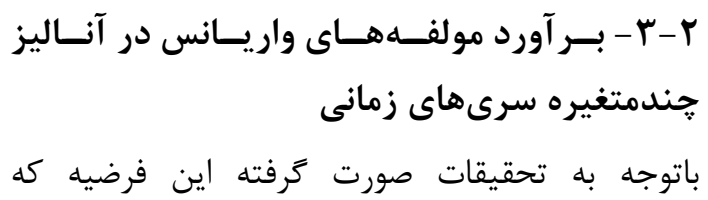


مورد بحث داراى جوابى نايايدار باشد .اما در اين مقاله نشان خواهيم داد كه همواره اين جنين نيست و و بسته

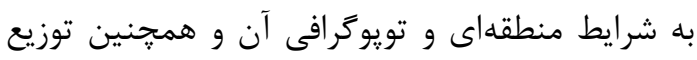

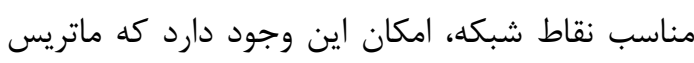

$$
\text { ضرايب بدوضع نخردد. }
$$

برخلاف نحرش تغيير شكل آيزويارامتريك كه بر اساس لاس

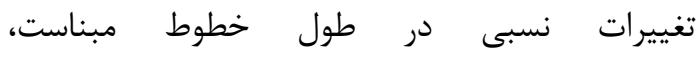

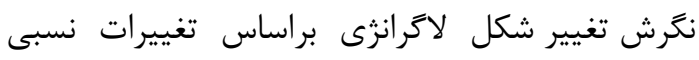

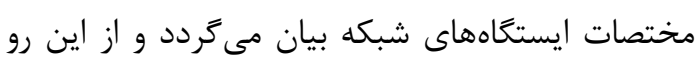

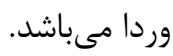

فرض كنيم كه تف $w=(x, y, z)$ تغيير شكل بيوسته جسم را توصيف مى كنند، آنكاه با باليا فرض نزديك بودن دو نقطه مىتوان جابهجايى نقاط بونئ نسبت به هم را به صورت زير نشان داد:

$\Delta u=\Delta x \frac{\partial_{u}}{\partial_{x}}+\Delta y \frac{\partial_{u}}{\partial_{y}}+\Delta z \frac{\partial_{u}}{\partial_{z}}$

رابطه (YI)

$\Delta v=\Delta x \frac{\partial_{v}}{\partial_{x}}+\Delta y \frac{\partial_{v}}{\partial_{y}}+\Delta z \frac{\partial_{v}}{\partial_{z}}$

$\Delta w=\Delta x \frac{\partial_{w}}{\partial_{x}}+\Delta y \frac{\partial_{w}}{\partial_{y}}+\Delta z \frac{\partial_{w}}{\partial_{z}}$

اين معادلات بر حسب يارامترهاى دوران و استرين و

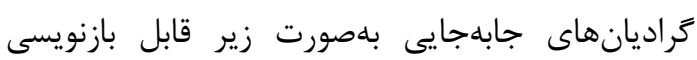
مى باشند :
براى برآورد مولفههاى واريانس در حالت حندمتغيره نيز تنها مىبايست برخى ترمها را در معادلات (• (1) و (11)

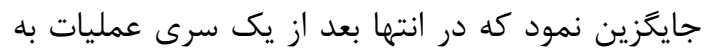

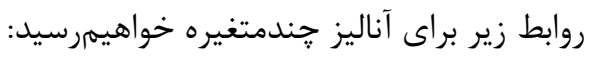

$$
\begin{aligned}
& \widehat{\sigma}=\mathrm{N}^{-1} \mathrm{~L} \\
& \text { رابطه (1) } \\
& \text { رابطه (19) }
\end{aligned}
$$

$\mathrm{n}_{\mathrm{kl}}=\frac{r}{2} \operatorname{tr}\left(\mathrm{Q}_{\mathrm{k}} \mathrm{Q}_{\mathrm{y}}^{-1} \mathrm{P}_{\mathrm{A}}^{\perp} \mathrm{Q}_{\mathrm{l}} \mathrm{Q}_{\mathrm{y}}^{-1} \mathrm{P}_{\mathrm{A}}^{\perp}\right)$

رابطه (·)

$\underline{\mathrm{l}}_{\mathrm{k}}=\frac{1}{2} \operatorname{tr}\left(\mathrm{Q}_{\mathrm{k}} \mathrm{Q}_{\mathrm{y}}^{-1} \mathrm{P}_{\mathrm{A}}^{\perp} \mathrm{Q}_{0} \mathrm{Q}_{\mathrm{y}}^{-1} \mathrm{P}_{\mathrm{A}}^{\perp}\right)$

\section{r- بآناليز استرين}

به دليل ماهيت سه بعدى بديده تغيير شكل زمين،

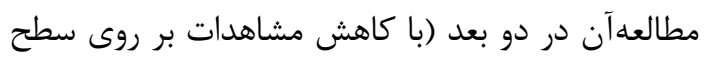

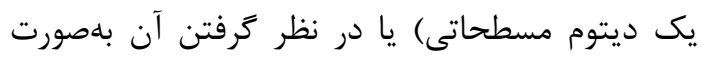

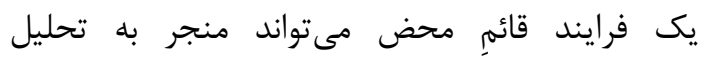
نادرستى از تغيير شكل شود. در اين مقاله در نظر دارئ داريم

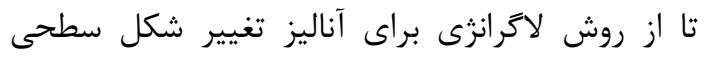

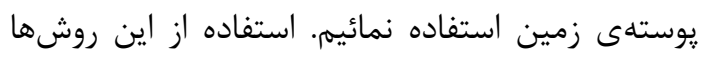

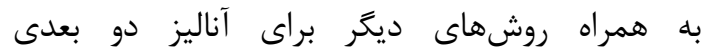

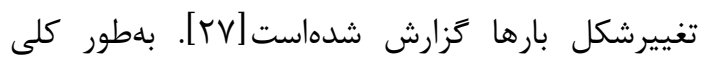

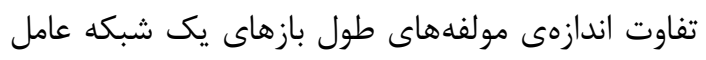
نايايدارى جواب در آناليز سه بعدى تغيير شكل شآل

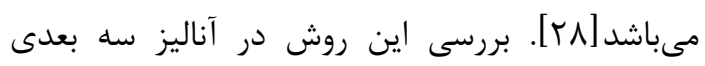

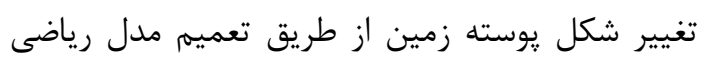

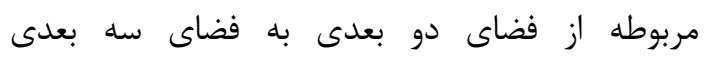
نشان مىدهد كه امكان اين وجود داردكة مسئله

رابطه (T)

$$
\begin{aligned}
& \Delta u=e_{x x} \Delta x+\frac{1}{2} e_{x y} \Delta y+\frac{1}{2} e_{x z} \Delta z-\omega_{z} \Delta y+\omega_{y} \Delta z \\
& \Delta v=\frac{1}{2} e_{x y} \Delta x+e_{y y} \Delta y+\frac{1}{2} e_{y z} \Delta z-\omega_{x} \Delta z+\omega_{z} \Delta z \\
& \Delta w=\frac{1}{2} e_{z x} \Delta x+\frac{1}{2} e_{y z} \Delta y+e_{z z} \Delta z-\omega_{y} \Delta x+\omega_{x} \Delta y
\end{aligned}
$$




$$
\begin{aligned}
& \text { ماتريس ضرايب براى اين روش به صورت زير نمايش داده مىشود : } \\
& \mathrm{A}=\left[\begin{array}{ccccccccc}
\Delta E_{k 1} & 0 & \frac{1}{2} \Delta N_{k 1} & 0 & \frac{1}{2} \Delta U_{k 1} & 0 & 0 & \Delta U_{k 1} & -\frac{1}{2} \Delta N_{k 1} \\
0 & \Delta N_{k 1} & \frac{1}{2} \Delta E_{k 1} & 0 & 0 & \frac{1}{2} \Delta U_{k 1} & -\Delta U_{k 1} & 0 & -\Delta E_{k 1} \\
0 & 0 & 0 & \Delta U_{k 1} & \frac{1}{2} \Delta E_{k 1} & \frac{1}{2} \Delta N_{k 1} & \Delta N_{k 1} & -\Delta E_{k 1} & 0 \\
\ldots & \ldots & \ldots & \ldots & \ldots & \ldots & \ldots & \ldots & \ldots \\
\Delta E_{k p} & 0 & \frac{1}{2} \Delta N_{k p} & 0 & \frac{1}{2} \Delta U_{k p} & 0 & 0 & \Delta U_{k p} & -\frac{1}{2} \Delta N_{k p} \\
0 & \Delta N_{k p} & \frac{1}{2} \Delta E_{k p} & 0 & 0 & \frac{1}{2} \Delta U_{k p} & -\Delta U_{k p} & 0 & -\Delta E_{k p} \\
0 & 0 & 0 & \Delta U_{k p} & \frac{1}{2} \Delta E_{k p} & \frac{1}{2} \Delta N_{k p} & \Delta N_{k p} & -\Delta E_{k p} & 0
\end{array}\right]
\end{aligned}
$$

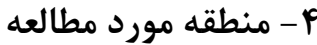

براى انجام اين يزوهش شبكهاى شامل 19 ايستكاه در

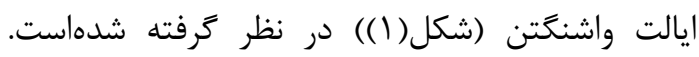

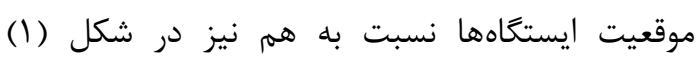
نمايش داده شدهاست. مشاهدات مربوط به به اين

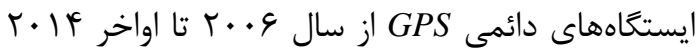

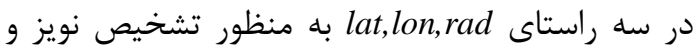

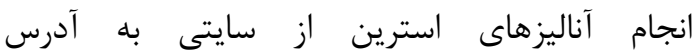
ml http://sideshow.jpl.nasa.gov/post/series.ht دانلود شدهاست.

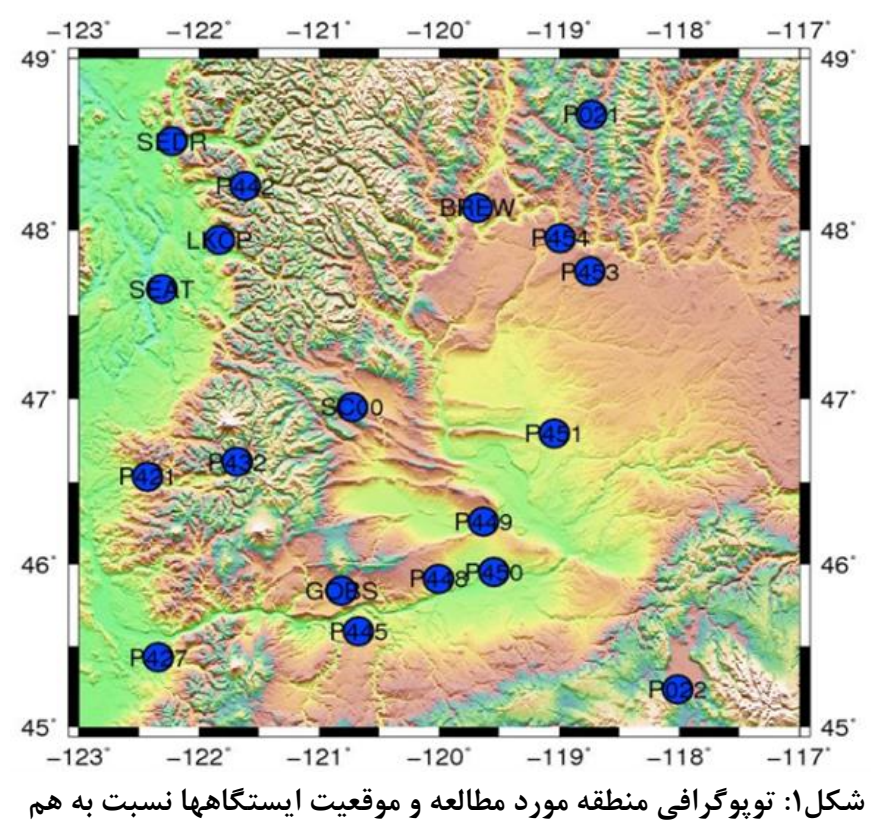

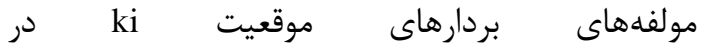
سيستم مختصات محلى ENU مى بـاشند .

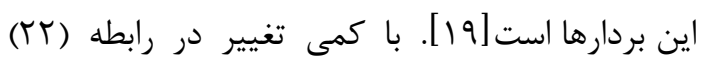

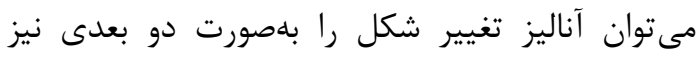

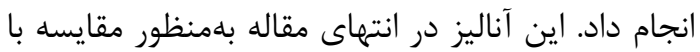
حالت سه بعدى انجام شدهاست. 


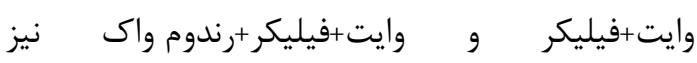

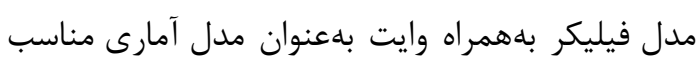

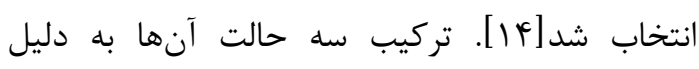

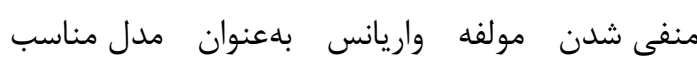

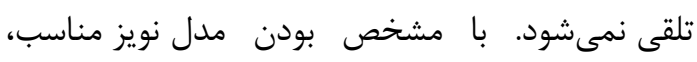

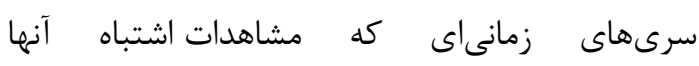

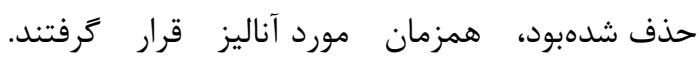

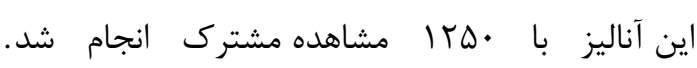

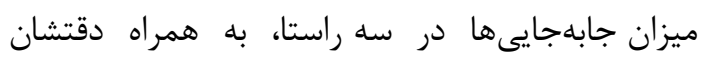

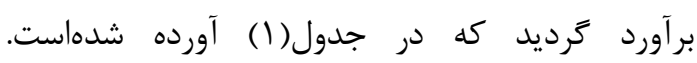

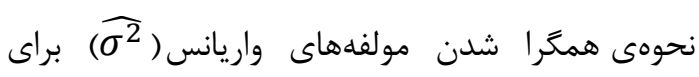

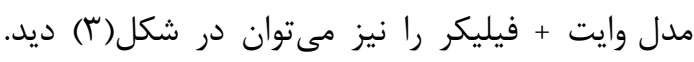

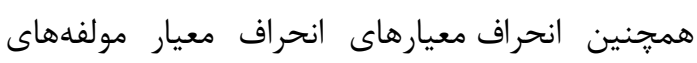
واريانس نيز در شكل(r) نشان داده شدهاست .

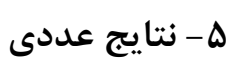

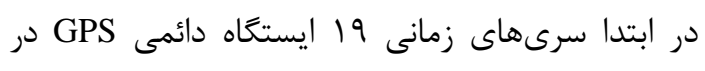

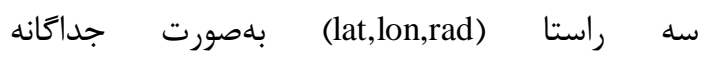
يردازش شدند. در جريان تردازش جداكانه يا تك تك راستا

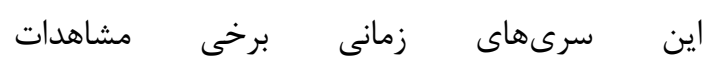

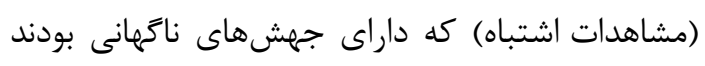
به كمك W-test تشخيص داده شدند و از روند يردازش

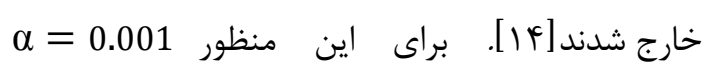

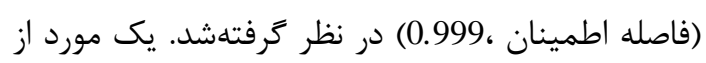
اين جهشها مربوط به سرى زمانى مولفهى lat ايستكاه BREW

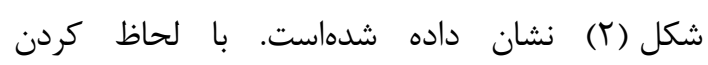

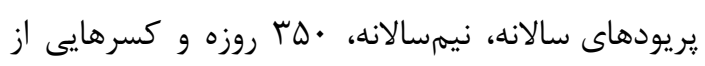

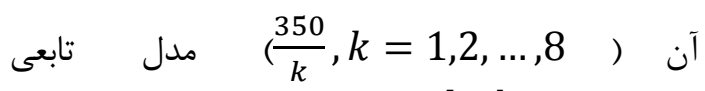

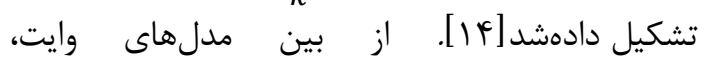

جدول ا: ميزان جابهجايىها (cm/year) در سه راستا به همراه دقت جابهجايىها در تعدادى از ايستعًاهها

\begin{tabular}{|c|c|c|c|c|c|c|c|}
\hline \multicolumn{2}{|c|}{ ايستگًاه } & \multicolumn{2}{|c|}{ Lat } & \multicolumn{2}{|c|}{ Lon } & \multicolumn{2}{|c|}{ Rad } \\
\hline شماره & ن & $\begin{array}{c}\Delta l a t \\
(\mathrm{~cm} / \mathrm{y})\end{array}$ & $\begin{array}{c}\sigma_{\Delta l a t} \\
(\mathrm{~cm} / \mathrm{y})^{2}\end{array}$ & $\begin{array}{c}\Delta l o n \\
(\mathrm{~cm} / \mathrm{y})\end{array}$ & $\begin{array}{c}\sigma_{\Delta l a t} \\
(\mathrm{~cm} / \mathrm{y})^{2}\end{array}$ & $\begin{array}{c}\Delta r a d \\
(\mathrm{~cm} / \mathrm{y})\end{array}$ & $\sigma_{\Delta l a t}(\mathrm{~cm} / \mathrm{y})^{2}$ \\
\hline 1 & $B R E W$ & -0.98 & 0.016 & -1.26 & 0.016 & -0.11 & 0.059 \\
\hline 2 & GOBS & -0.84 & 0.017 & \begin{tabular}{|c|}
-1.27 \\
\end{tabular} & 0.017 & -0.16 & 0.055 \\
\hline 3 & $L K C P$ & -0.89 & 0.020 & -1.08 & 0.018 & -0.17 & 0.069 \\
\hline 4 & $P 021$ & -1.02 & 0.018 & -1.30 & 0.016 & -0.03 & 0.057 \\
\hline 5 & P022 & -0.96 & 0.019 & -1.37 & 0.023 & -0.07 & 0.067 \\
\hline 6 & $P 421$ & -0.68 & 0.017 & -0.90 & 0.017 & 0.09 & 0.061 \\
\hline 7 & $P 427$ & -0.65 & 0.016 & -1 & 0.017 & -0.20 & 0.054 \\
\hline 8 & $P 432$ & -0.81 & 0.020 & -1.07 & 0.021 & -0.16 & 0.066 \\
\hline 9 & $P 442$ & -0.90 & 0.024 & -1.15 & 0.019 & -0.15 & 0.065 \\
\hline 10 & $P 445$ & -0.87 & 0.018 & -1.23 & 0.017 & -0.2 & 0.061 \\
\hline
\end{tabular}




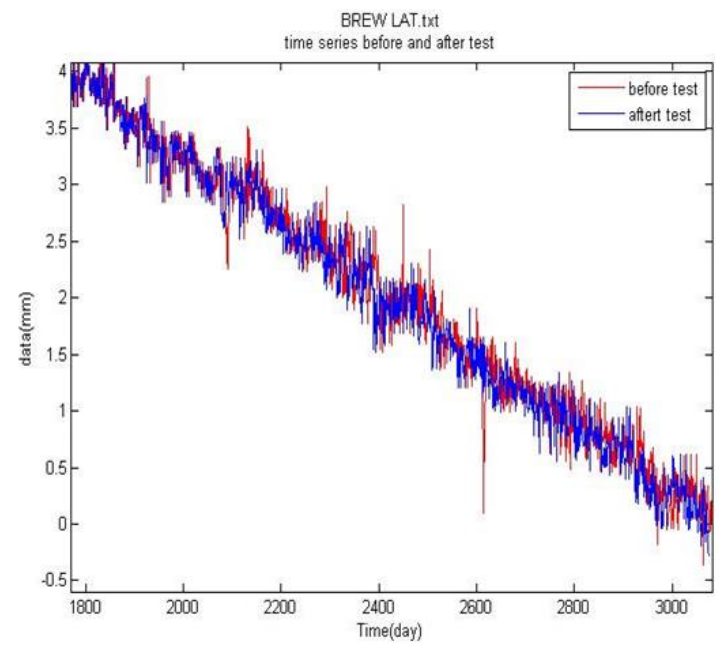

ش شكل r: حذف مشاهدات اشتباه از سرى زمانى با 0.001

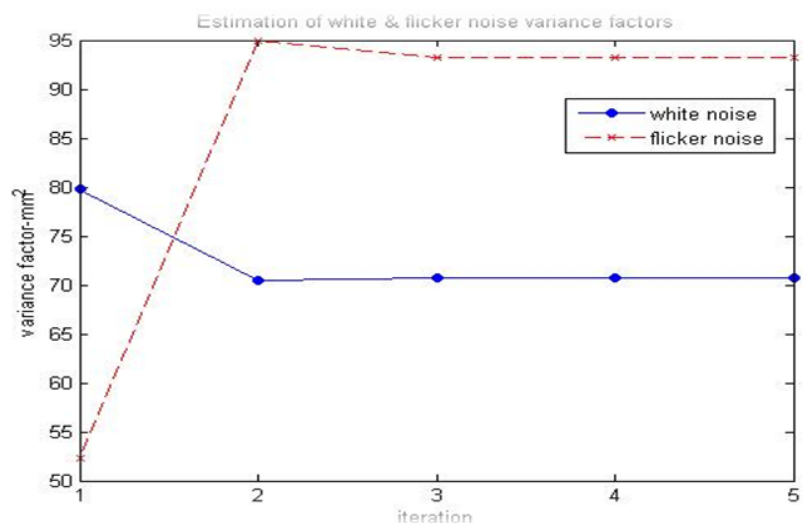

شكل ب: نحوهى همكرا شدن مولفههاى واريانس در آناليز جندمتغيره (مدل وايت + فيليكر)

$$
\left(\sigma_{\widehat{\sigma}} w=0.003, \sigma_{\widehat{\sigma}} f=0.012\right)
$$

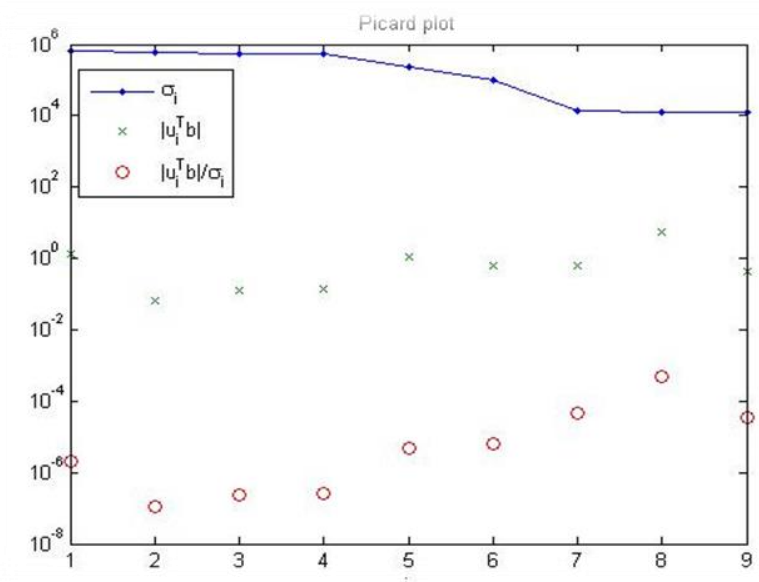

شكل F: برقرار بودن شرط يِيكارد براى مسئله آناليز تغيير شكل سه بعدى لآرانزى در منطقه مورد مطالعه 
(به لحاظ تويوكرافى) كه در شكل (1) نشان دادهشد،

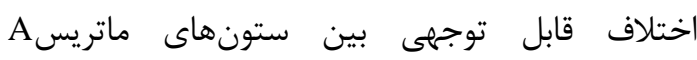
ديده نمىشود. اين عدم اختلاف قابل توجه را مى توان

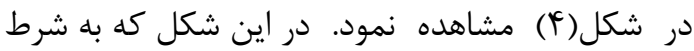

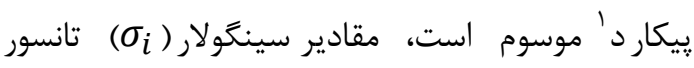

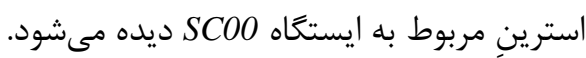
نكتهى ديكر، كميتهاى ناوردا در تانسور استرين

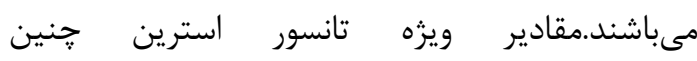

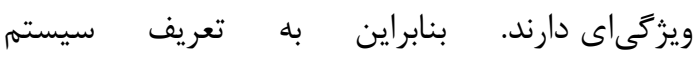

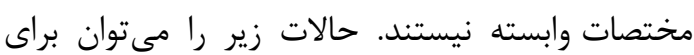

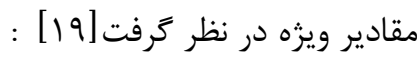

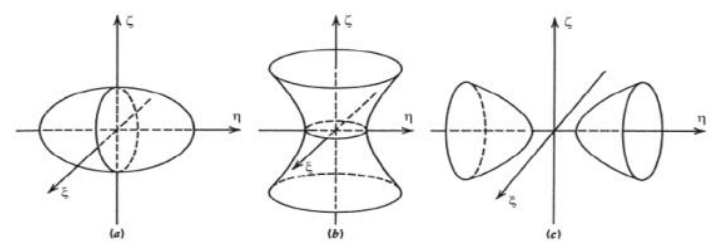

شكله: اشكال هندسى معادله درجه دو تغيير شكل در سه بعد

ا. در حالت (a): هر سه مقدار ويزه مثبت

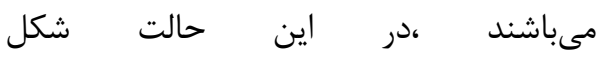

حاصل بيضوى است و در هر سه جهت ايند انبساط وجود خواهد داشت.

ז. در حالت (b): دو مقدار مثبت مىباشند

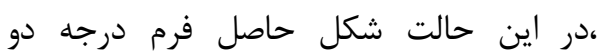

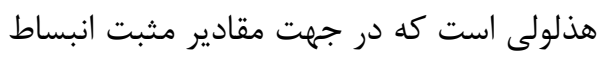
و در جهت مقدار منفى انقباض وجود دارد. r. در حالت (c): يك مقدار مثبت است و بنابراين

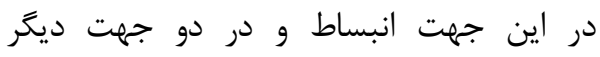
فشردگى وجود دارد. آر

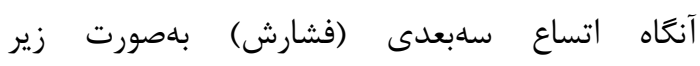

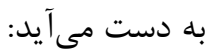
$E=\Lambda_{1}+\Lambda_{2}+\Lambda_{3}$ رابطه (Tr)

${ }^{1}$ Picard Condition
همان كونه كه اشاره شد با تعميم مدل رياضى از دو بعد

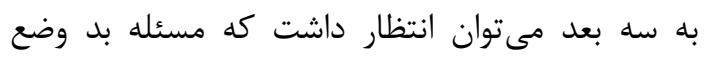

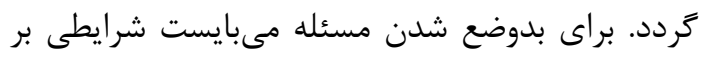

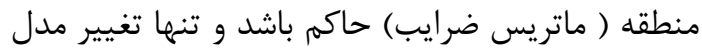

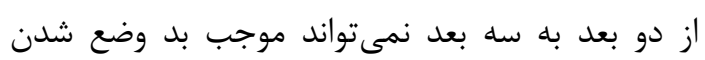

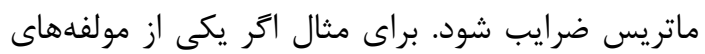
طول بازهاى بين نقاط يك شبكه صفر باشد (زمانى كه

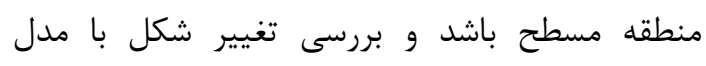

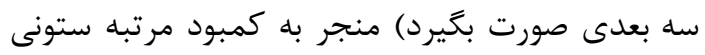
ماتريس ضرايب مى خردد در نتيجه مسئله نايايدار

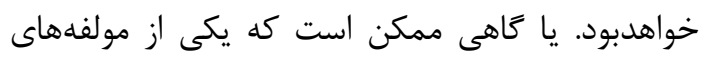

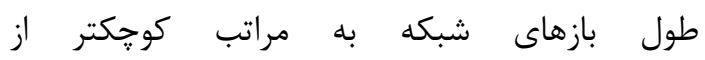

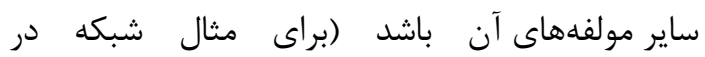

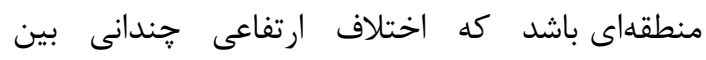

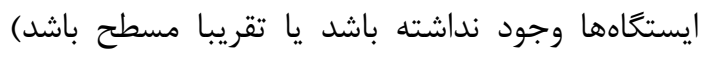
در اين شرايط عدد شرط ماتريس (نسبت بزركترين

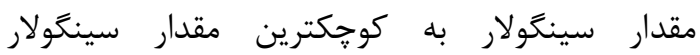

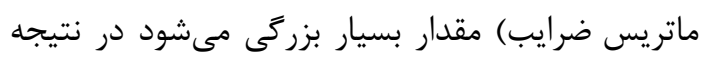

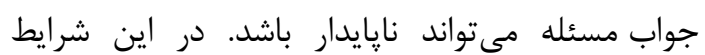
مولفههاى

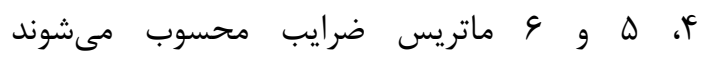
حساسيت بيشترى نسبت به تغييرات يارامترهاى ورودى خواهند داشت. مى توان به مشهدى حسينعلى و همكاران اشاره كرد كه نايايدارى جواب كمترين

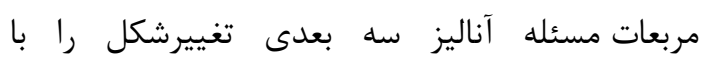

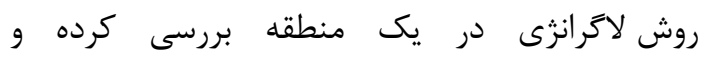
نشان دادند كه جواب حاصل از روش كمترين مربعات

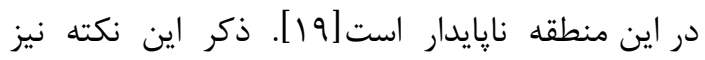

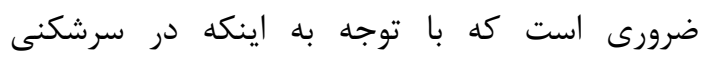

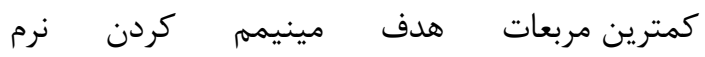

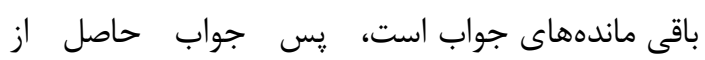

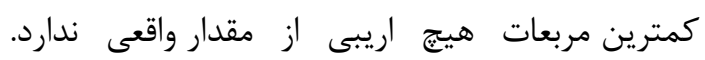

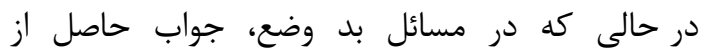

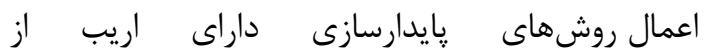
مقدار واقعى خواهد بود. با توجه به شرايط مايط منطقهاى اري 
سه بعدى، تصوير روشنترى را در خصوص الگوى تغيير شكل مسطحاتى (

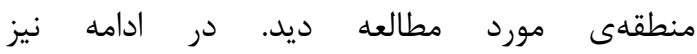

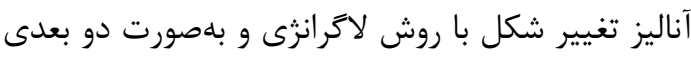

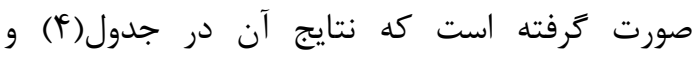

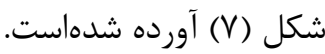

در حالت دو بعدى نيز با فرض آنكه $\lambda_{2} \lambda_{2}$

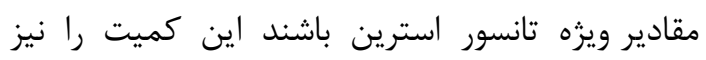
مىتوان بهصورت زير به دست آورد: $e=\lambda_{1}+\lambda_{2}$

رابطه (TY)

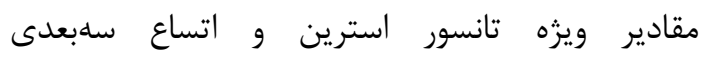

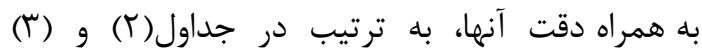
ارائه شده است. همجنين در شكل (9) مى توان با آناليز

جدول r: اعداد شرط، مقادير ويزه و دقت آنها در روش آناليز تغيير شكل لاكرانزى به صورت سه بعدى در تعدادى از ايستكاهها

\begin{tabular}{|c|c|c|c|c|c|c|c|c|}
\hline \multicolumn{2}{|r|}{ ايستتًاه } & \multicolumn{6}{|c|}{ مقادير ويزه به همراه دقت آنها در آناليز تغيير شكل به صورت سه بعدى } & \multirow{2}{*}{ شدر } \\
\hline شماره & نام & $\Lambda_{1}$ & $\sigma_{\Lambda_{1}}$ & $\Lambda_{2}$ & $\sigma_{\Lambda_{2}}$ & $\Lambda_{3}$ & $\sigma_{\Lambda_{3}}$ & \\
\hline 1 & BREW & $-4.7 e-06$ & $7.53 e-07$ & $3.1 e-06$ & $6.17 e-07$ & $2.4 e-05$ & $3.84-07$ & 171 \\
\hline 2 & GOBS & $-1.9 e-05$ & $6.31 e-07$ & $1.2 e-06$ & $5.82 e-07$ & $4.86 e-05$ & $6.7 e-07$ & 146 \\
\hline 3 & LKCP & $-7.04 e-06$ & $9.19 e-07$ & $3.07 e-06$ & $6.84 e-07$ & $4.7 e-05$ & $2.3 e-07$ & 186 \\
\hline 4 & P021 & $-6.63 e-05$ & $8.64 e-07$ & $2.01 e-06$ & $7.06 e-07$ & $1.37 e-04$ & $5.33 e-07$ & 224 \\
\hline 5 & P022 & $-1.41 e-04$ & $8.5 e-07$ & $-5.95 e-06$ & $7.7 e-07$ & $1.87 e-04$ & $3.9 e-07$ & 207 \\
\hline 6 & P421 & $-1.99 e-06$ & $6.8 e-07$ & $2.51 e-06$ & $2.18 e-07$ & $5.69 e-05$ & $4.06 e-07$ & 190 \\
\hline 7 & P427 & $-5.16 e-05$ & $9.62 e-07$ & $4.99 e-07$ & $7.41 e-07$ & $1.57 e-04$ & $4.18 e-07$ & 197 \\
\hline 8 & $\mathrm{P} 432$ & $-3.13 e-05$ & $9.4 e-07$ & $3.92 e-06$ & $9.27 e-07$ & $4.46 e-05$ & $3.4 e-07$ & 127 \\
\hline 9 & P442 & $-7.6 e-06$ & $4.69 e-07$ & $2.63 e-06$ & $1.67 e-07$ & $6.8 e-05$ & $7.81 e-07$ & 191 \\
\hline 10 & P445 & $-1.45 e-06$ & 1.e-06 & $5.79 e-07$ & $3.92 e-07$ & $4.15 e-05$ & $1.47 e-07$ & 181 \\
\hline
\end{tabular}

جدول ץ: مقادير اتساع سه بعدى به همراه دقت بر آورد آنها در آناليز تغيير شكل لاكرانزى به صورت سه بعدى

در تعدادى از ايستخاهها

\begin{tabular}{|c|c|c|c|}
\hline \multicolumn{2}{|r|}{ ايستخاه } & \multicolumn{2}{|c|}{ اتساع سه بعدى } \\
\hline شماره & نام & $E$ & $\sigma_{E}$ \\
\hline 1 & BREW & $2.25 e-05$ & $9.85 e-07$ \\
\hline 2 & GOBS & $3.04 e-05$ & $9.94 \mathrm{e}-07$ \\
\hline 3 & LKCP & $4.3 e-05$ & $9.87 \mathrm{e}-07$ \\
\hline 4 & P021 & $7.27 e-05$ & $1.01 \mathrm{e}-06$ \\
\hline 5 & P022 & $4.07 e-05$ & $9.44 \mathrm{e}-07$ \\
\hline 6 & P421 & $5.74 e-05$ & $9.83 e-07$ \\
\hline 7 & P427 & $1.06 e-04$ & $1.05 \mathrm{e}-06$ \\
\hline 8 & P432 & $1.72 e-05$ & $1.03 \mathrm{e}-07$ \\
\hline 9 & P442 & $6.3 e-05$ & $9.88 \mathrm{e}-07$ \\
\hline 10 & P445 & $4.06 \mathrm{e}-05$ & $9.86 \mathrm{e}-07$ \\
\hline
\end{tabular}


شاهد يلهاى شدن محسوسِ مقادير سينكولار

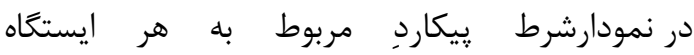
ستون آخر جدول(r) شامل اعداد شرط مىباشد. نخواهيم بود. در نتيجه مىتوان با اطمينان بيشترى

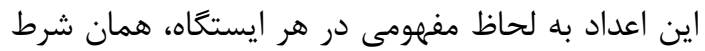

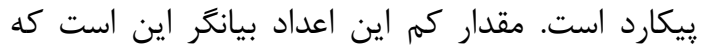
نتايج بدستآمده را تفسير كرد.

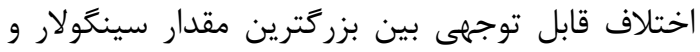

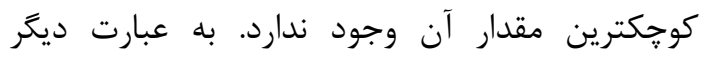

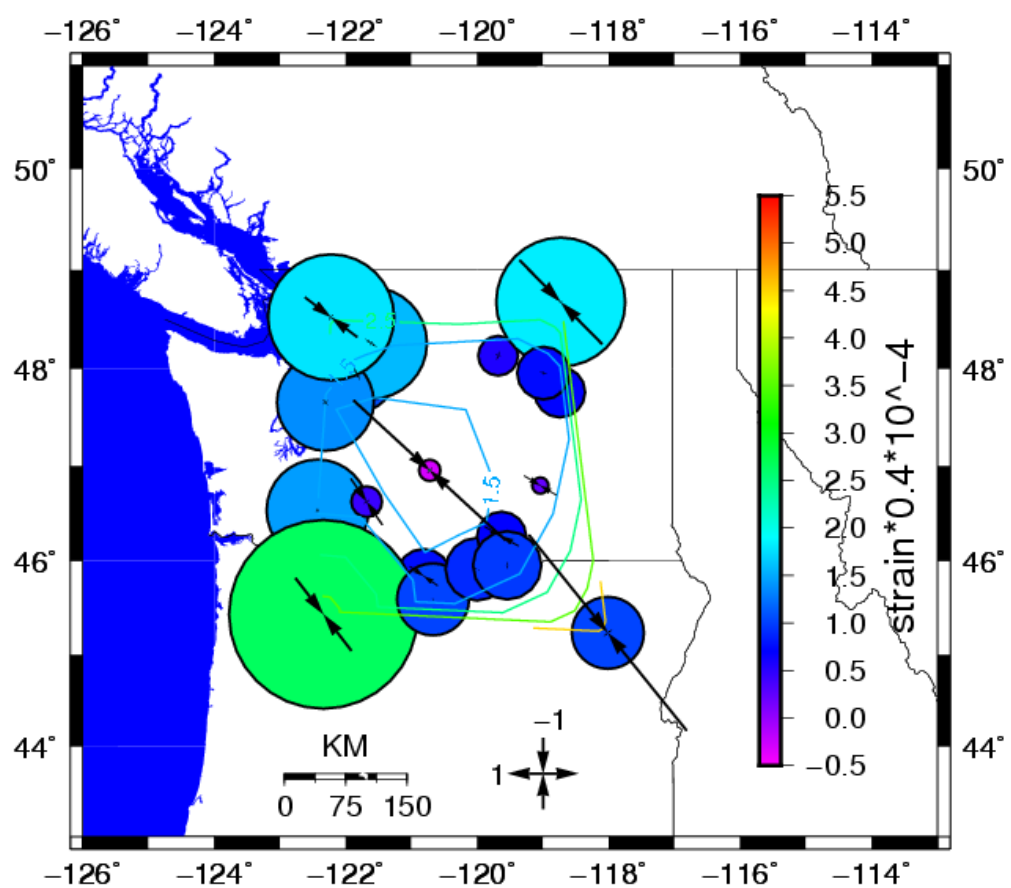

شكل \&: مولفههاى مسطحاتى و ارتفاعى تانسور كرنش و مقادير اتساع(دايرهها) در آناليز تغيير شكل لاترانزى به صورت سهبعدى جدول F: مقادير ويزه و دقت آنها به همراه اتساع در روش آناليز تغيير شكل لاكر انزى به صورت دو بعدى در ت تعدادى از ايستخاهها

\begin{tabular}{|c|c|c|c|c|c|c|c|}
\hline \multicolumn{2}{|c|}{ ايستخاه } & \multicolumn{4}{|c|}{ مقادير ويزه به همراه دقت آنها } & \multicolumn{2}{|c|}{ اتساع دو بعدى } \\
\hline شماره & 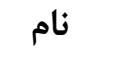 & $\lambda_{1}$ & $\sigma_{\lambda_{1}}$ & $\lambda_{2}$ & $\sigma_{\lambda_{2}}$ & $e$ & $\sigma_{e}$ \\
\hline 1 & BREW & $-8.93 e-07$ & $3 e-08$ & $1.25 e-06$ & $3.59 e-08$ & $3.62 e-07$ & $4.66 e-08$ \\
\hline 2 & GOBS & $-1.44 e-06$ & $2.94 e-08$ & $2.96 e-06$ & $3.41 e-08$ & $1.52 e-06$ & $4.63 e-08$ \\
\hline 3 & LKCP & $-1.32 e-06$ & $3 e-08$ & $2.5 e-06$ & $3.44 e-08$ & $1.17 e-06$ & $4.56 e-08$ \\
\hline 4 & $\mathrm{P} 021$ & $-8.32 e-07$ & $2.98 e-08$ & $6.33 e-07$ & $3.66 e-08$ & $-1.99 e-07$ & $4.59 e-08$ \\
\hline 5 & P022 & $-1.31 e-06$ & $3.07 e-08$ & $1.97 e-06$ & $3.24 e-08$ & $6.62 e-07$ & $4.74 e-08$ \\
\hline 6 & P421 & $-1.55 e-06$ & $2.95 e-08$ & $3.07 e-06$ & $3.43 e-08$ & $1.51 e-06$ & $4.58 e-08$ \\
\hline 7 & $\mathrm{P} 427$ & $-1.77 e-06$ & $3.01 e-08$ & $3.6 e-06$ & $3.47 e-08$ & $1.83 e-06$ & $4.72 e-08$ \\
\hline 8 & $\mathrm{P} 432$ & $-1.41 e-06$ & $2.92 e-08$ & $2.89 e-06$ & $3.46 e-08$ & $1.47 e-06$ & $4.56 e-08$ \\
\hline 9 & P442 & $-1.24 e-06$ & $3.01 e-08$ & $2.27 e-06$ & $3.49 e-08$ & $1.02 e-06$ & $4.58 e-08$ \\
\hline 10 & $\mathrm{P} 445$ & $-1.48 e-06$ & $2.95 e-08$ & $2.99 e-06$ & $3.42 e-08$ & $1.5 e-06$ & $4.67 e-08$ \\
\hline
\end{tabular}




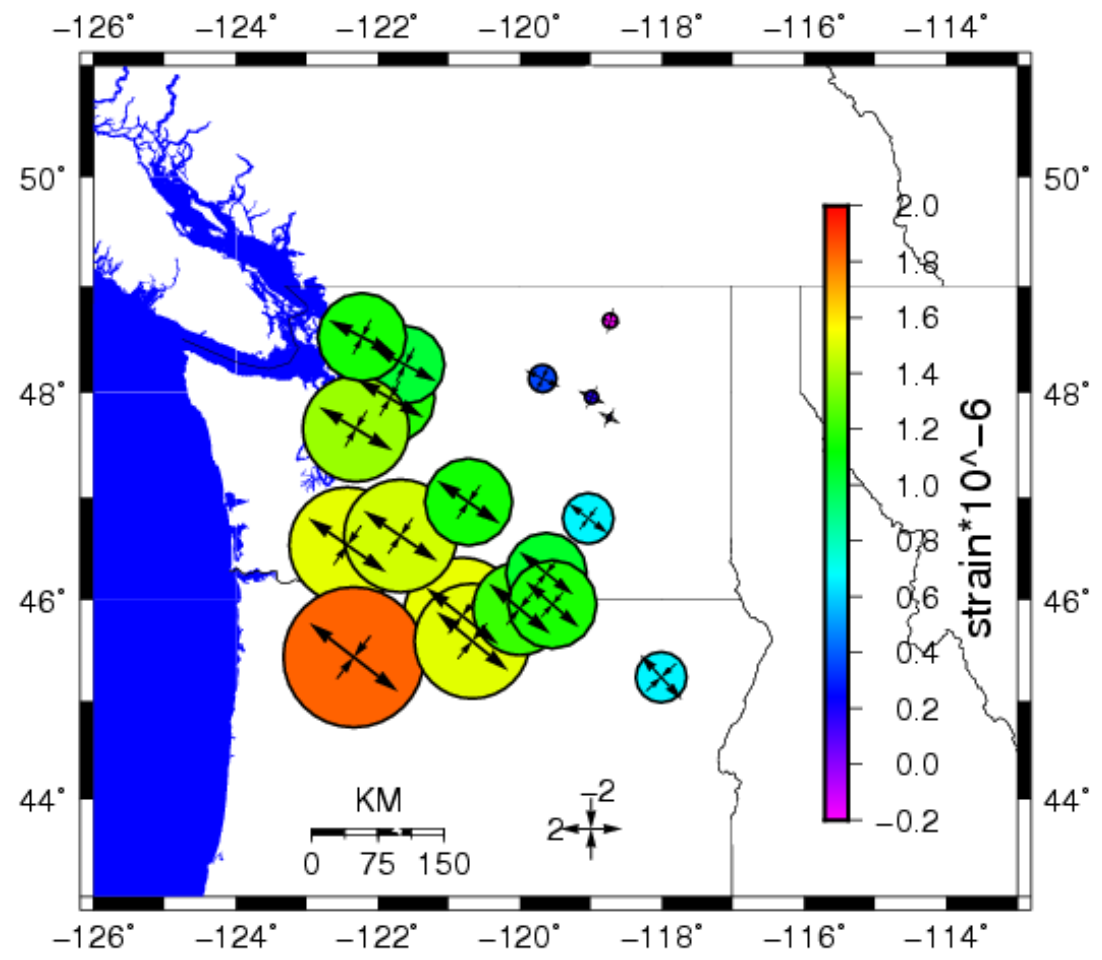

شكل V: مولفههاى مسطحاتى تانسور كرنش و مقادير اتساع(دايرهها) در آناليز تغيير شكل لاكرانزى به صورت دو بعدى

صرف نظر كردن از اثر مولفهى ارتفاعى و بررسى به

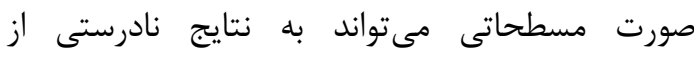

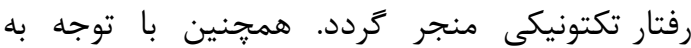

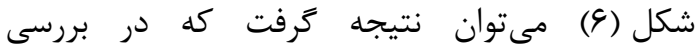
تغيير شكل در حالت سه بعدى در بيشتر ايستخاهها شاهد هذلولى استرين مىباشيمه.

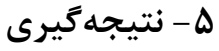

ييوستخى در سرى هاى زمانى ايستخاهماى دائمى GPS

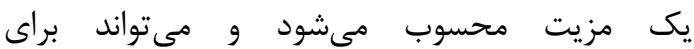
آشكارسازى تغييرات و جابهجايىها مورد استفاده

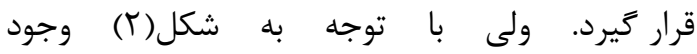
برخى مشاهدات اشتباه يا يرشها كه به offset يا jump موسوم هستند (براى مثال مىتوانند ناشى از انبساط و

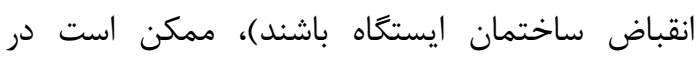
صورت عدم توجه، رفتار تكتونيكى تلقى شده و منجر به

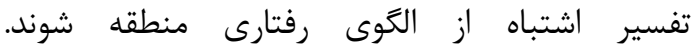

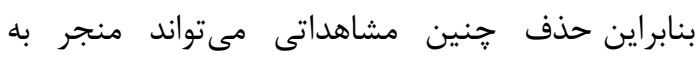

نكته جالب توجه اينكه الگوى تغيير شكل تا حد زيادى

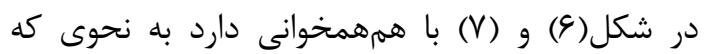
ميزان فشارش، در هر دو روش در ايستخاه (p427) بيشترين مقدار را داراست. در بيشتر ايستخاهها نيز مى توان اين همخوانى را به وضوح ديد. اما نكته مهمى كه وجود دارد اين است: از آنجا كه اين مسئله در حالت سهبعدى در منطقه مورد مطالعه نايايدار نيست يس مى توان با اطمينان بيشترى نسبت به نتايج به تحليل رفتار تكتونيكى منطقه يرداخت .با مقايسه نتايج حاصل از دو روش (آنجه كه در جداول و اشكال

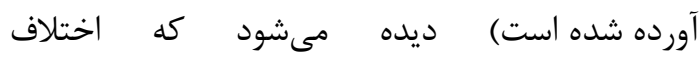
بسيار قابل توجهى بين مقادير وجود دارد كه كاه

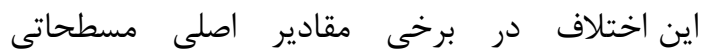
تانسور استرين و مقادير فشارش به دو رقم اعشار نيز مىرسد (به منظور مقايسه به شكل(Y) و (V) و جداول

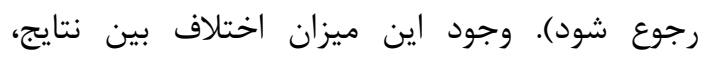
تاكيدى است بر اهميت بررسى رفتار تكتونيكى منطقه بهصورت سه بعدى و نه جداكانه. به عبارت ديخر 


$$
\begin{aligned}
& \text { مىشود. از آنجا كه هدف در سرشكنى كمترين مربعات } \\
& \text { رسيدن به جوابى ناوردا است، عدم طراحى صحيح }
\end{aligned}
$$

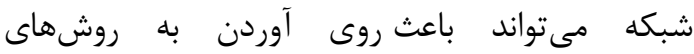

$$
\begin{aligned}
& \text { يايدارسازى گردد كه منجر به دستكارى مسئله و نهايتاً }
\end{aligned}
$$

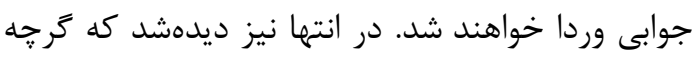

$$
\begin{aligned}
& \text { الكَوهاى رفتارى منطقه در هر دو روشي آناليز، با هم دماند }
\end{aligned}
$$

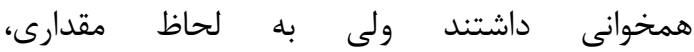

$$
\begin{aligned}
& \text { اختلاف قابل توجهى بين مقادير وجود داشت. اين امر دانئن } \\
& \text { مىتواند بيانكر اهميت بررسى رفتئ رفتار تكتونيكى منطقه }
\end{aligned}
$$

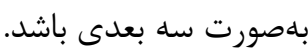

[1] Bock Y, et al (1997) Southern California Permanent GPS Geodetic Array: Continuous measurements of regional crustal deformation between the 1992 Landers and 1994 Northridge earthquakes. J Geophys Res 102(B8):1801318033

[2] Zhang J, Bock Y, Johnson H, Fang P, Williams S, Genrich J, Wdowinski S, Behr J (1997)Southern California permanent GPS geodetic array: error analysis of daily position estimates and sitevelocitties. J Geophys Res 102:18035-18055

[3] E. Calais, "Continuous GPS measurements across the Western Alps, 1996-1998," Geophysical Journal International, vol. 138, no. 1, pp. 221-230, 1999.

[4] A. Mao, C. G. A. Harrison, and T. H. Dixon, "Noise in GPS coordinate time series," Journal of Geophysical Research, vol. 104, no. B2, pp. 2797-2816, 1999.

[5]S. D. P. Williams, Y. Bock, P. Fang, P. Jamason, R. M. Nikolaidis, L. Prawirodirdjo, M. Miller, and D. J.Johnson, "Error analysis of continuous GPS position time series," Journal of Geophysical Research, vol.109, no. B3, p. B03412, 2004.

[6] Langbein, J. and H. Johnson (1997). "Correlated errors in geodetic time series: Implications for time-dependent deformation." Journal of Geophysical Research: Solid Earth (1978-2012) 102(B1): 591-603.

[7] Dong, D., P. Fang, Y. Bock, M. K. Cheng,

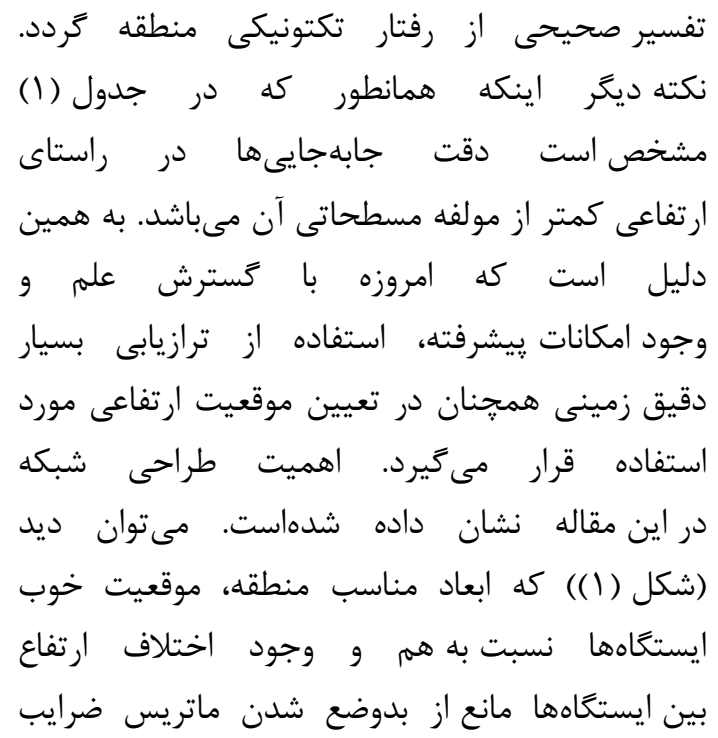

مراجع

and S. Miyazaki (2002), "Anatomy of apparent seasonal

variations from GPS-derived site position time series", J. Geophys. Res., 107(B4), 2075, doi:10.1029/2001JB000573.

[8] van Dam TM, Wahr J (1987) Displacements of the Earth's surface due to atmospheric loading: Effects on gravity and baseline measurements. J Geophys Res 92:1281-1286

[9] van Dam, T., J. Wahr, P. C. D. Milly, A. B. Shmakin, G. Blewitt, D. Lavalle'e, and K. M. Larson (2001),Crustal displacements due to continental water loading, Geophys. Res. Lett., 28(4), 651- 654.

[10] StewartMP, Penna NT, Lichti DD (2005)." Investigating the propagation mechanism of unmodelled

systematic errors on coordinate time series estimated using least squares". J Geod 79:479489. doi: 10.

1007/s00190-005-0478-6

[11] Penna NT, KingMA, StewartMP (2007)." GPS height time series: Shortperiod origins of spurious long period signals". J Geophys Res 112(B02402). doi:10.1029/2005JB004047

[12] Penna, N. and M. Stewart (2003). "Aliased tidal signatures in continuous GPS height time series." Geophysical Research Letters 30(23).

[13] Collilieux, X., et al. (2007). "Comparison of very long baseline interferometry, GPS, andsatellite laser ranging height residuals from ITRF2005 using spectral and correlation methods." Journal of Geophysical Research: 


\section{Solid Earth (1978-2012) 112(B12).}

[14] A. Amiri-Simkooei, "Least-Squares estimation of variance components, theory and GPS applications," Doctoral dissertation, Delft University of Technology, Netherlands, 2007.

[15] H. Sadeghi and B. Vosooghi, Estimation of velocity of displacement using GPS time series (Khorasan province) and maximum likelihood method, Geomatics meeting, Tehran, 2010. (Persian

[16] Grafarend, E. W. (1986): Threedimensional deformation analysis: Global vector spherical harmonic and local element representation: Tectonophysics, 130: 337-359.

[17] Brunner F.K., 1979, "On the analysis of geodetic networks for the determination of the incremental strain tensor." Survey Review XXV 192:56-67.

[18] Voosoghi, B. (2000), Intrinsic Deformation Analysis of the Earth Surface Based on 3Dimensional

Displacement Fields Derived From Space Geodetic Measurements. PhD thesis, Institute of Geodesy,Universit"at Stuttgart, Germany.

[19] Hossainali , M. M. (2005), "A Comprehensive Approach to the 3D-Analysis of Deformation", Ph.D.

Thesis, TU-Darmstadt.

[20] Amiri-Simkooei, A. (2009). "Noise in multivariate GPS position time-series." Journal of Geodesy 83(2): 175-187.

[21] Zhang, J., et al. (1997). "Southern California Permanent GPS Geodetic Array: Error analysis of daily position estimates and site velocities." Journal of Geophysical Research 102(B8): 18035-18018,18055

[22] Mao, A., et al. (1999). "Noise in GPS coordinate time series." Journal of Geophysical Research: Solid Earth (1978-2012) 104(B2): 2797-2816.

[23] Johnson, H. and F. Wyatt (1994). "Geodetic network design for fault-mechanics studies."Manuscripta geodaetica 19(5): 309.

[24] B. Schaffrin, "Best invariant covariance component estimators and its application to the generalize

multivariate adjustment of heterogeneous deformation observations," Journal of Geodesy, vol. 55 , no. 1 ,

pp. 73-85, 1981.

[25] P. J. G. Teunissen and A. R. AmiriSimkooei, "Least-squares variance component estimation," Journal of Geodesy, vol. 82, no. 2, pp. 65-82, 2008.

[26] A. R. Amiri-Simkooei, "Noise in multivariate GPS position time-series," Journal of Geodesy, vol. 83, no. 2,pp. 175-187, 2009.

[27] Chen, R. (1991). On the horizontal crustal deformations in Finland. Helsinki, Finish Geodetic Institute.

[28] Hossainali, M.M., Becker, M., E. Groten E. (2011): Comprehensive Approach to the Analysis of the 3D Kinematics Deformation with application to the Kenai Peninsula, Journal of Geodetic Science. 


\title{
Three dimensional Lagrangian strain analysis using GPS time series without regularization (Case study: Washington)
}

\author{
Yashar Tode Zaeem ${ }^{1}$, Vahab Nafisi ${ }^{2}$, Alireza Amiri Simkooii ${ }^{3}$
}

\footnotetext{
1- Msc graduated of Geodesy, Department of Geomatics Engineering, Faculty of Engineering, University of Isfahan

2- Assisstant professor,Department of Geomatics Engineering, Faculty of Engineering, University of Isfahan

3- Associate professor, Department of Geomatics Engineering, Faculty of Engineering, University of Isfahan
}

\begin{abstract}
Earth deformation is a three-dimensional phenomenon; therefore crust analysis also must be done in threedimension. Analysis of deformation using two epochs can be replaced by analysis of time series, which is more effective for modeling of geodynamics phenomena. GPS permanent stations provide such observations. At the first part of this study, time series of 19 GPS permanent stations in Washington region have been used. With simultaneous analysis of common observations, displacements in three directions were obtained. According to the obtained results, estimation accuracy of horizontal displacements is nearly 3.5 times better than estimation accuracy of vertical displacements. In the next section, Lagrangian method has been used to analyze the deformation. Generally, by generalization of the mathematical model of this method, from two-dimensional to three-dimensional, there is a possibility of problem's instability. The results of this study show that generalized three-dimensional model necessarily does not lead to instability of the problem. It seems that position of points relative to each other and topography of the region are more important elements which can make coefficients matrix ill-conditioned. As an important point, we can mention that deformation pattern obtained using twodimensional and three-dimensional analysis are consistence. This consistency can be obviously found in most stations. But in terms of values, we can find serious differences between horizontal main values of strain tensors and compression values even up to two decimals. These differences may come from ignoring vertical component in analysis of two-dimensional deformation.
\end{abstract}

Key words: time series ‘condition number ، ill-condition problem.

Correspondence Address: Department of Geomatics Engineering, Faculty of Engineering, University of Isfahan Email: vnafisi@gmail.com, nafisi@eng.ui.ac.ir 